\title{
Cerebral Visual Impairment
}

National Cancer Institute

\section{Source}

National Cancer Institute. Cerebral Visual Impairment. NCI Thesaurus. Code C118710.

Visual impairment due to central nervous system dysfunction. 